\title{
研究報告
}

\section{アルミニウム合金の等温時効曲線に 関する考察}

\section{菅野 幹宏** 鈴木 寿** 系井 一博**}

Some considerations on isothermal aging curves of aluminum alloys*

UDC 669. 715:621.785.7

KANNO Motohiro**, SUZUKI Hisashi** and ITOI Kazuhiro**

Isothermal aging curves of various aluminum alloys have been of ten plotted against logarithm of aging time. However, the discussion on the shape and slope of these curves is usually done without taking serious considerations on the time scale. In this paper, some significant differences between the logarithmic and the linear plotting were discussed. The results obtained were as follows:

(1) Even in the situation where the aging occurs monotonously with an increasing rate, which itself decreases as the aging proceeds, the aging curve can take a complicated form when the logarithmic time scale is adopted; it can have an incubation period, abrupt acceleration, a two stage change, etc, depending on the increasing rate.

(2) It has been found that if most of the aging curves, reported previously, are replotted in the linear time scale, the shapes of these curves become very simple, and the complicated features seen in the logarithmic expression disappear.

(3) It is proposed, therefore, that the various previous considerations on the shape of the aging curve in the logarithmic expression should be reexamined.

(Received December 28, 1973)

\section{1. 緒 言}

時効硬化型アルミニウム合金の研究といえば，ここ何 年かの間ほとんどが格子欠陷論的立場からなされ，それ ぞれ興味ある諸結果が報告され，時効曲線の形状変化に ついてもその物理的意味がしばしば論議されてきた。と ころでその場合時効曲線の描記法を見ると, 長時間時効 に対しては $\log (l$, 時効時間) プロットが便利であるた め, 得られる曲線を対象に形状変化の物理的意味が多く の報文で述べられてきてしまつた。時間軸が $\log t$ か $t$ であるかについては十分の注意が必要と思われるが，従 来の報文ではこれがあまり考虑されておらず，問題を含 む記述などが見受けられるようである。

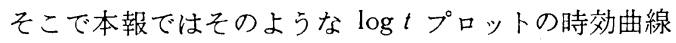
の形状から何を言いうるのかを詳しく考察し，関係記述
の不十分な点を明らかにしたいと考えた。

\section{2. 方 法}

ここでは特に奉験は行なわず，まず $\log t$ プロット曲 線のむつ意味を考えるため, $\log t$ プロット曲線と $t 7^{\circ}$ ロット曲線の形状比較に関するじやつかんの数学的検討 を行なつた。その後この結果をふまえ, Al-Cu, Al-Cu $-\mathrm{Mg}, \mathrm{Al}-\mathrm{Zn}-\mathrm{Mg}$ などの合金において知られている時效 曲線の形状を $\log t$ プロットと $t$ プロットの雨側から考 察し，その本質的相違を明らかにし，また彷来の関倸論 文から具体的な例を引用し，それを検討した。これより $\log t$ プロット曲線の特異性を無視してその形状变化を 直接的に物理的変化に結びつけることの危除性を示すこ とにした。

* 軽金属学会第45回秋期大会 (48-11)にて発表した。

** 東京大学工学部 (東京都) Faculty of Engineering University of Tokyo (Tokyo). 


\section{3. 考察}

Fig. 1 は模式的な $\log t$ プロットの時効曲線例で曲線 A はいわゆる潜伏期を経た後上昇しその後減少するとい う単純な一段変化曲線である。これに対し曲線 B は I に おける急激な上昇の後，Iのプラトーを経てIIIで再び急 激な上昇があり後減少するいわゆる 2 段変化曲線であ る。このような曲線形状の定義ははじめ $\mathrm{Al}-\mathrm{Cu}$ 合金の 硬化曲線についてなされだ”。これを Fig. 2 に示す。こ の後間もなく本硬化曲線と析出相との関係づけが Fig. 3 のような形で行なわれ ${ }^{2)}$ ，上記合金の曲線形状に意味が あると考えられるようになつた。ところが他の合金系に おいても時効曲線がこのような形状となる場合が多く， その場合は 1 段目あるいは 2 段目の急激な変化を $\mathrm{Al}-\mathrm{Cu}$ 合金の例にならつてただちに内部構造の変化に基づくと 思われてきたようである゙)。組織的検定を行なわずに $\log t$ プロット曲線におけるこの種の変化をただちに物理 的変化と直結させてよいのであろうか。この点をまず1 段変化のA 型曲線について考えてみよう。

Fig. 4 はよく知られた諸関数 $X=f(t)$ を $\log t$ でプ ロットした場合の模式図である。いずれの曲線にも変化

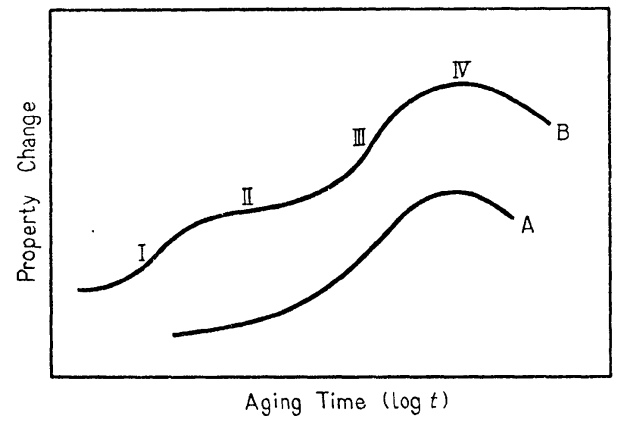

Fig. 1 Schematic drawing of isothermal aging curves exprssed in the using logarithmic time scale.

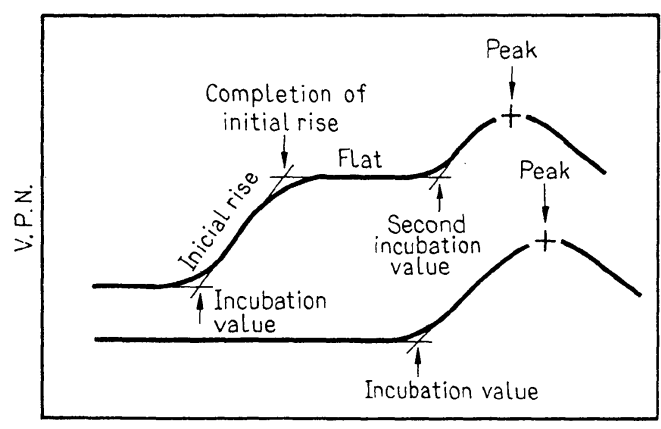

$\log t$

Fig. 2 The definition and terminology of aging curves by Hardy. ${ }^{1)}$
のゆるやかないわゆる潜伏期がみられ，後に急激に上昇 する。しかし $X=f(t)$ を $t$ プロットすればもちろんの ことこのよらな潜伏期と曲線の急上昇は生じない。すな わち Fig. 4 の変化は $\log t$ プロットによる短時間側の拡 大と長時間側の縮少に帰因する。これをわかりやすく示 せば,

$$
d x / d(\log t)=t \cdot d x / d t
$$

であるから $\log t$ プロットの場合， $X=f(t)$ の増加率 (または減少率) $d X / d t$ が単調減少の場合であつても, $t$ が著しく大の領域では増加率（减少率） $d X / d(\log t)$ は初 期の值に比べ急増（急減）する場合を生じる。そのよう な場合Fig. 4 (b, c, d) にも見られるように増加率単調減 少の増加関数 (または減少率単調減少の減少関数) の $\log t$ プロット曲線には， $t$ プロット曲線には認められない見 かけ上の急激な上昇(低下)が現われることになる。実際 にAl-Cu合金をはじめとする各種合金において見かけ上 潜伏期と急激な変化を示す $\log t$ プロットの一段変化曲 線を $t$ プロットすると, それらはすべて時効初期に変化 量が最大となる単調増加(減少)曲線となつた。これまで はこのような $\log t$ プロット曲線の見かけ上の変化をと らえて，長時間の潜伏期の後突然諸性質が変化する。そ してこの変化は中間相, 安定相の析出によるとしていた ようであるが4),5)，この記述は明らかに妥当でない。

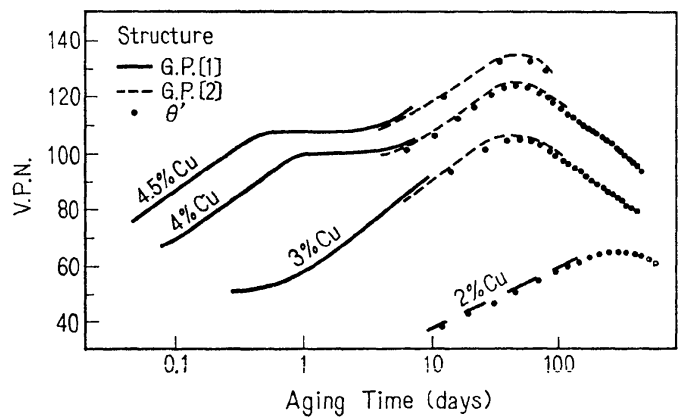

Fig. 3 Structures at $130^{\circ} \mathrm{C}$ in relation to hardness vs. aging time curves of $\mathrm{Al}-\mathrm{Cu}$ alloys, by Silcock et al. ${ }^{2)}$

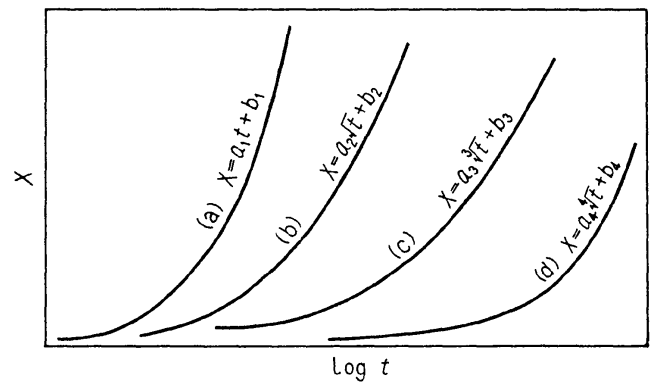

Fig. 4 Schematic drawing of curves expressed semilogarithmically for some increasing functions. 
つぎに時効曲線の 2 段変化については，次式 $d^{2} X \mid d(\operatorname{lcg} t)^{2}=t \cdot\left(t \cdot d^{2} x / d X^{2}+d X / d X\right)$

より $X=f(t)$ が前記同様増加率単調減少の 増 加 関 数 $\left(d X / d t>0, d^{2} X / d t^{2}<0\right)$ であつても, $t, d^{2} X / d t^{2}, d X / d t$ の值 いかんによつては $d^{2} X / d(\log t)^{2}=0$ も起こりらる。し たがつてそのような場合は， $X=f(t)$ を $t$ プロットし た曲線に変曲点が見られなくても, $\log t$ プロット曲線に はそれが現われる。しかも $d^{2} X / d(\log t)^{2}=0$ を満足する $t$ の值は一般に 1 つとは限らず, 複数となり,そのような 場合には $\log t$ プロット曲線に多数の変曲点が出現する。 また $X=f(t)$ がたとえば $X=\sqrt{t}, \sqrt[3]{t}, \sqrt[4]{t}$ などの 諸関数から合成されている場合を考えると，Fig. 4 から 見てその $\log t$ プロット曲線には複数の段を生じること が理解できる。以上により従来しばしば問題にされてき た $\log t$ プロット曲線の形状変化，たとえば 2 段硬化な どはすべて $\log t$ プロットに基づく見かけ上の所産とも 考えられる。

ここで以下 $2 ， 3$ の具体例を挙げて考察したい。2 段 硬化曲線は $\mathrm{Al}-\mathrm{Cu}$ 合金において最も著名であるが，他 の合金についても報告されている ${ }^{6)}$ 。また $\mathrm{Al}-\mathrm{Cu}-\mathrm{Mg}$ 合 金では 3 段硬化曲線の報告 ${ }^{7)}$ 8) もある。しかしながらこ れら $\log t$ プロットの時効曲線を著者らが $t$ プロットし なおすと, 曲線の変化速度は初期に最大となり単純な増 加を示し, 後減少するという単純な硬化曲線となり, そ のよらな段は認められなかった。さらに2 段硬化すると される $\mathrm{Al}-\mathrm{Cu}$ 合金の $\log t$ プロットの時効曲線の中には $3 ， 4$ 段変化のように見える曲線も存在し*，各時効段 階で析出相の同定を行なつた結果 ${ }^{2)}$ (Fig. 3 を参照) を見 ると複数の相が共存する場合がある。したがつて $\mathrm{Al}-\mathrm{Cu}$ 合金に限定しても第 1 段硬化が G. P. [I] ゾーンにより, 第 2 段硬化が G. P. [II] ゾーンによるとする見解は，か つて Hardy ら ${ }^{11)}$ が提唱したものではあつたが，一般性 があると考えられない。まして他の合金系において $\mathrm{Al}$ $\mathrm{Cu}$ 合金の類推から 2 段硬化を意味づけるのは，もはや 時効現象の誤認に近い。

さて，比抵抗変化曲線の形状についても理解しにくい 考察がかなり多い。たとえば微量の $\mathrm{Mg}$ を含む $\mathrm{Al}-\mathrm{Zn}-$ $\mathrm{Mg}$ 合金の低温時効遅滞の機構の検討 $\left.{ }^{10}\right)$ に際し, $\mathrm{Al}-\mathrm{Zn}$ 合金では $\log t$ プロットの比抵抗曲線が 1 段変化するの に対し，微量の $\mathrm{Mg}$ を含む合金では 2 段変化が現われる ことに注目して次のように考察する。 $\mathrm{Mg}$ を含む合金に
生じた初期の段は $\mathrm{Zn}, \mathrm{Mg}$ を含む 3 元のゾーン形成によ つて生じるとし，さらにこのゾーンが焼入過剩空孔を捕 獲するため Zn リッチゾーンの形成がおくれ， 2 段変化 すなわち低温時効遅滞を生じたと考察する。しかしジー ン形成に伴う比抵抗変化は焼入直後に増加速度が最大で あり，時効の進行と共に時効速度を低下するのが普通で あること祀を考えると，上記のように見かけ上の時効曲 線の形状変化をただちに異種ゾーンの形成に結びつける のはいきすぎであろら。事実, 上述の曲線を著者らが $t$ プロットしてみると $\mathrm{Al}-\mathrm{Zn}-\mathrm{Mg}$ 合金の比抵抗曲線は, $\mathrm{Al}-\mathrm{Zn} 2$ 元合金より変化速度はやや小さいものの，2 元 合金の場合と同様いわゆる fast およびslow reactionをも つ通常の形状となつた。なお付言すれば本合金の低温時 効遅滞機構は，3 元ゾーンとかいわゆるVacancy Trapping 説 ${ }^{12), 13)}$ とは関係のないことがすでに明らかにされ ている ${ }^{14)}$ 。上述の例も $\log t フ^{\circ}$ ット曲線における見か け上の変化**を直接内部の物理的変化と結びつけた妥当 性を欠く例である。

また最近 $\mathrm{Al}-\mathrm{Zn}-\mathrm{Mg}$ 合金について, $\log \mathrm{t}$ プロットの比 抵抗変化曲線に生じる停留 (Fig. 1 のプラトーに当たる) に注目しこれを熱処理条件との関係 G. P. で，ゾーン, 中間相の形成に関連するとする報文 ${ }^{15)}$ もる。この見か けの停留も比抵抗の変化速度が適当であつたため（(2)式 参照) $\log t$ プロットによつて生じただけであり， $t$ プ ロット曲線には出現するはずはない。

さてすでに述べたようにlog ほとんどの場合潜伏期がみられるようである。Hardy は $\mathrm{Al}-\mathrm{Cu}$ 合金においてこのような見かけの潜伏期と時 効温度 (絶対温度, $T_{A}$ ) の逆数との関係からFig. 5 に示 すような $\mathrm{C}$ 曲線を描き，低温部の $\mathrm{C}$ 曲線は G. P. [I] ゾ ーン，高温部のそれは G. P. [II] ゾーンによつて生じる とした。また彼は $\mathrm{Al}-\mathrm{Cu}-\mathrm{Mg}$ 合金においても同様な解析 を行なつた ${ }^{8)}$ が，この場合は時効曲線が見かけ上 3 段変 化をするにもかかわらず，結果的にはいわゆる C曲線 を得ることに失敗し, 直線を描いてしまつた。その後 Polmear ${ }^{16), 17)}$ は Al-Zn-Mg 系合金の種々の時効温度に おける硬化曲線を基に, Hardy同様潜伏期と $1 / T_{A}$ の関係 から Fig. 6に示すような 2 つノーズを有するC曲線を 描き，その交叉する温度をもつてこの系合金の G. P. 相 固溶限温度*** とした。しかし原論文をよく見るとすで

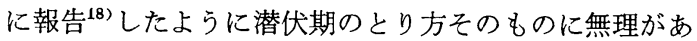

* 見方によつては 2 段時効とされる曲線が 3 段または 4 段変化にも見え，その他高温時効で 1 段変化とされる曲線 にも $2 ， 3$ 段変化に見えるものがある11,9)。

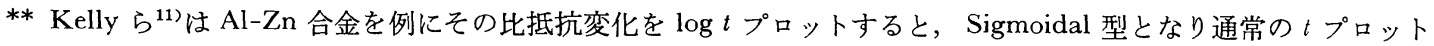
とは形状が異なることに留意するが，その検討はしていない。

*** この值は著者らが $(\alpha+\mathrm{T})$ 型 $\mathrm{Al}-\mathrm{Zn}-\mathrm{Mg}$ 合金において比抵抗によつて定められたもの ${ }^{18)}$ よりも $30 \sim 35^{\circ} \mathrm{G}$ 高く信 頼性に乏しいと考えられる。 


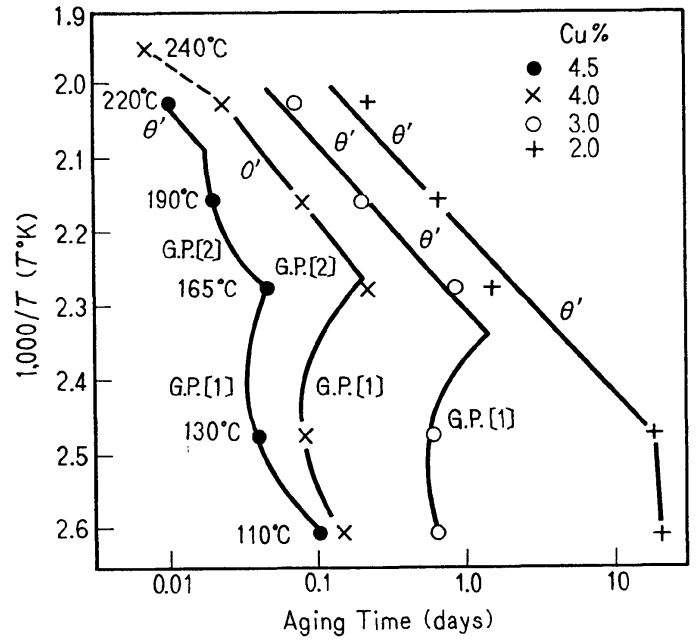

Fig. 5 Temperature/incubation value relationships for Al-Cu alloys, by Hardy. ${ }^{9)}$

り問題がある。またくり返し述べるように, いわゆる潜 伏期はこの場合をも含めて $\log t$ プロットの所産であり, したがつてそのような見かけ上の潜伏期と $1 / T_{A}$ の関係 からC曲線を求めたり, さらには G. P. ゾーンの固溶温 度を定めることなどは，上記の例と同様意味がない。

一般に相変態, そして析出現象の場合にも潜伏期が存 在すると考えられてきているが，著者らが検討した限り では見かけのもの以外に真の潜伏期（ $t$ プロットでも生 じる）と思われるものは観察されないように思われる。 この点については今後核生成論との関連で検討を要しよ 5 。

以上 $\log t$ プロットの時効曲線の形状について種々検 討してきたが，当初の予想通り，1 段変化における潜伏 期およびその後の急激な上昇， 2 段変化などは $\log t$ プ ロットによるみかけ上のものであり， $t$ プロットではす ベて単純な曲線となることが確かめられた。したがつて このような 2 段変化を組織検討を行なわずに，物理的意 味があるかのよらに考察してきた従来の関係記述はほと んど意味を失い，反省の必要があろう。

\section{3. 結 論}

アルミニウム合金の等温時効曲線の形状について $\log t$ プロット曲線と $t$ プロット曲線との比較検討を行ない, つぎの諸結果を得た。

(1)増加率単調减少の単調増加関数を $\log t$ プロットす るといわゆる潜伏期, 急激な上昇などが出現する場合が あり $(t$ プロットではみられない), また変化率に依存し て，1 段以上の多段曲線となりらることをまず示した。 (2)実際にAl-Cu 合金を初めとする多くのアルミニウム 合金系における $\log t$ プロット曲線を $t$ プロットし直し

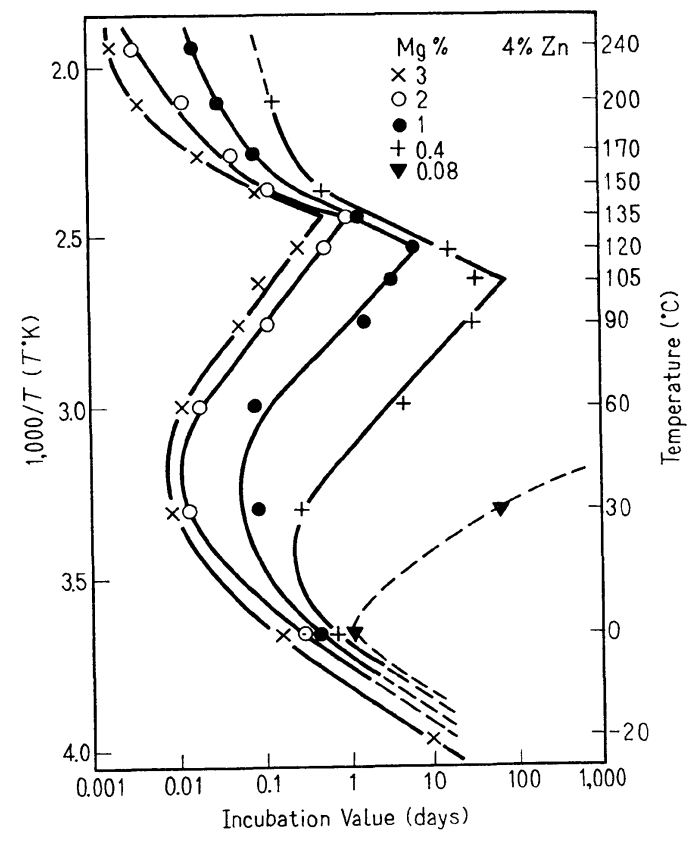

Fig. 6 Temperature/incubation value relationships for $\mathrm{Al}-\mathrm{Zn}-\mathrm{Mg}$ alloys, by Polmear. ${ }^{16)}$

てみると，それらはすべて単純な形状となり，潜伏期は 現われず，1段，2段あるいはそれ以上の多段曲線とな ることのないことを確かめた。

(3)したがつて，これまでこのような $\log t$ プロット曲 線の形状変化をとらえて，たとえば 2 段変化を析出相と 直接関係づけたり，溶質／原子空孔間の相互作用を論じ たり，潜伏期と時効温度の逆数との関係から C曲線を論 じるなどがなされてきたが，それらは物理的意味に欠け るものであることを指摘した。

\section{参考文献}

1) H. K. Hardy: J. Inst. Metals, 79 (1951), 321.

2) J. M. Silcock, T. J. Heal and H. K. Hardy: J. Inst. Metals, $82(1953 \sim 54), 239$.

3) たとえば松尾：軽金属， 20 (1970), 205.

4) たとえば堀内，箕西：日本金 属 学 会 誌，34 (1970)，936.

5) たとえば馬場：日本金属学会誌，36 (1972)， 335.

6) たとえば麻田, 山本 : 軽金属, 21 (1971), 168 .

7) M. Cohen: Trans. A. I. M. E., 133 (1939), 95.

8) H. K. Hardy: J. Inst. Metals, 83 (1954 55), 17.

9) H. K. Hardy: J. Inst. Metals, $82(1953 \sim 54)$, 236.

10) M. Ohta and F. Hashimoto: J. Phys. Soc. Japan, 19 (1964), 1337.

11) たとえば A. Kelly and R. B. Nicholson: Progress in Materials Science, 10 (1961), 149, 
Pergamon press.

12) H. Kimura and R. R. Hasiguti: Acta Met., 9 (1961), 1076.

13) A. J. Perry: Acta Met., 12 (1964), 270.

14）鈴木，菅野，福永：軽金属, 22 (1972), 286.

15）添田，近崎：日本金属学会誌，37 (1973),
658.

16) I. J. Polmear: J. Inst. Metals, $86(1957 \sim 58)$, 113.

17) I. J. Polmear: J. Inst. Metals, 87 (1958 59), 24.

18）鈴木，菅野，浅見：軽金属，22（1972），269. 